ingeniously interdependent these facets are: the illustrations are not just attractive but they are required and used to support the concise style of the text. At the same time, the student is provided with a graphic framework into which complex concepts often seem to sit with comfort.

Every author of a basic biochemistry textbook is faced with two decisions: first, at what level to pitch the book and second where to begin and end. Stryer seems to aim unashamedly for the "early undergraduate", yet the brevity of the text often belies its depth: the author has a unique ability to expound difficult concepts in a few words. As biochemistry constitutes a bridge between physical and biological sciences, the limits are difficult to define and, regardless of how far apart the covers are, it would be impossible to satisfy every whim. Here the subject matter is very broadly based and the student is required to accumulate background knowledge of the physical sciences, organic chemistry, cell biology and basic molecular genetics from elsewhere. Nevertheless, one of the strengths of this textbook is that it can be

\section{Whole chemistry?}

\section{Peter Garratt}

Chemistry: An Introduction to General, Organic, and Biological Chemistry. By Joanne M. Widom and Stuart J. Edelstein. Pp.799. ISBN 0-7167-1224-5. (W.H. Freeman: 1981.) $\$ 23.95$, £16.60. Atoms, Molecules, and Life: An Introduction to General, Organic, and Biological Chemistry. By Michael S. Matta and Antony C. Wilbraham. Pp.721. ISBN 0-8053-9640-3. (Benjamin/Cummings: 1981.) $\$ 22.95$, £14.95. Basic Chemistry of Life. By Milton Toporek. Pp.521. Pbk ISBN 0-8016-5002-X. (C.V. Mosby: 1981.) $\$ 7.95, £ 12$.

THESE three texts are all directed at North American students of the life sciences and each presupposes little previous exposure to chemistry. Chemistry and Atoms, Molecules, and Life (AML) declare the same interest in their mutual subtitle, while the third, Basic Chemistry of Life (BCL), intends to provide a base in chemistry on which the student may build an understanding of the complex processes of life.

How are they to do this in less $(B C L$ considerably less) than 1,000 pages? Clearly there must be selection and much of the treatment must be superficial. For example, atomic structure is treated by $B C L$ in six pages and no student could have any basis for a further understanding of this subject after reading these. Both of the other books treat this topic in more detail, Chemistry making a valiant attempt to promote the ideas of quantum mechanics, whereas AML is rather cloudy on this issue. appreciated before the background is complete.

It is not surprising that this second edition is bigger than the first. Neither is it surprising that many of the illustrations in the first edition have been updated and many more have been added; a major effort has been made to get across the concept of the integration of metabolic processes and the text has been extended greatly to accommodate major advances in the subject, particularly in the area of molecular biology.

Textbooks for major subjects often present a daunting prospect where they should foster the enthusiasm of the student and provide a realistic challenge. The response to Stryer is generally enthusiastic: for a textbook, that is an accolade. The only penalties for confronting so massive a task may be that the compact style sometimes excludes subtlety and may not leave room for mystery, the solving of which will provide the material for the next edition. $\square$

Peter H.W. Butterworth is Reader in Biochemistry at University College London.

Chemical bonding is initially introduced in all three texts by "dot formulae", Chemistry and AML developing the subject further to indicate the threedimensional shape of molecules. All of the texts attempt to provide a foundation in physical chemistry, with an emphasis on those topics of interest to biologists. Electrolytes and non-electrolytes, solubility, osmosis and $\mathrm{pH}$ are all discussed in some detail and illustrated with biological examples; thus, for example, osmosis is described by the effect of changes in extracellular salt concentration on the red blood corpuscles. Each book includes a substantial section on organic chemistry, starting with methane and ending with nucleic acids and the genetic code. Both AML and BCL have extensive sections on biochemistry.

Of the three, $\mathrm{BCL}$ has the most medically orientated approach, the least basic chemistry and would require considerable elaboration on the part of the lecturer to give the student any real understanding of the subject. It virtually ignores the three-dimensional structure of molecules, and conformation is no where introduced. The consequences of threedimensional structure is an area in which none of these texts is consistently satisfactory; thus although AML shows that the steroids are chair structures, it does not indicate how this influences the sterenchemistry of the system, whilst Chemistry, though clearly indicating the stereochemistry, does not mention the conformational consequences. All of the texts use Haworth formulae for the carbohydrates and although Chemistry does introduce the conformational formula for glucose it does not exploit it. Chemistry, as its title suggests, is most clearly directed towards the exposition of this science and, starting from the four elements and ending with global

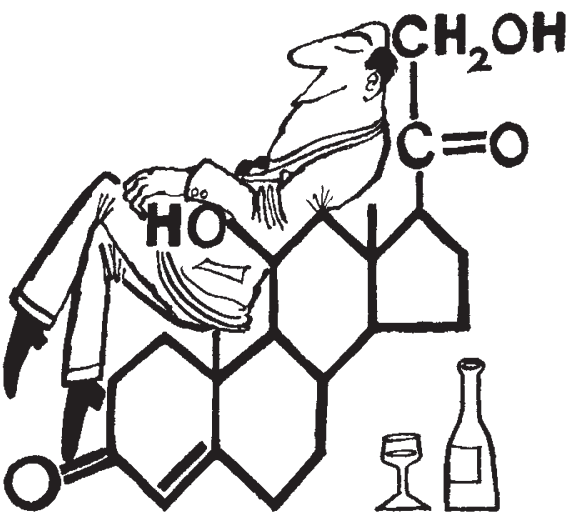

biochemical problems, it represents an impressive attempt to encompass both the essential and the exciting new aspects of the subject within a single volume.

The print of all three books is excellent and chemical structures are clearly illustrated, Chemistry and AML in twotone, BCL in monochrome. Each provides problems, often with answers, and Chemistry has available both a study guide for the student and a manual for the instructor. The latter provides answers for those questions without textual answers, test questions and suggestions for demonstrations.

Peter Garratt is Reader in Chemistry at University College London.

\section{Beyond description}

\section{H. Hassall}

Basic Mathematics for Biochemists. By Athel Cornish-Bowden. Pp.137. Hbk ISBN $0-412-23000-3$; pbk ISBN 0-412-23010-0. (Chapman \& Hall/ Methuen: 1981.) Hbk £7.95, \$17.95; pbk $\{3.95, \$ 8.95$. Quantitative Problems in Biochemistry, 6th Edn. By Edwin A. Dawes. Pp.335. ISBN 0-582-44402-0. (Longman: 1980.) £13.95, \$32. Biochemistry: A Problems Approach. By William B. Wood et al. Pp.498. ISBN 0-8053-9840-6. (Benjamin/Cummings: 1980.) \$14.95, £8.95.

YEAR after year, with only one or two exceptions, the questions that are done least well in biochemistry examinations are those involving calculations and data assessment. Mass panic ripples through the examination rooms and those painstakingly constructed subtleties of the examiners, the diauxic inflections of the growth curve, the sigmoidicity of the Michaelis-Menten graph or the slight curvature of the Yphantis plot, are either missed or explained as experimental error. 